\title{
Effects of Climate Change on Crop Production in Thaba-Tseka and Mokhotlong Districts Lesotho Highlands
}

\author{
Thobei $^{1,}$ Sutarno ${ }^{2}$ and Komariah ${ }^{3}$ \\ 1) Sebelas Maret University \\ 2) Ministry of Forestry and Land Reclamation \\ Department of Environmental Science, Sebelas Maret University, Surakarta, Indonesia.
}

\begin{abstract}
Climate change is a major and lasting change and has impact on agriculture. This study presents research results on effects of climate change on crop production in Thaba-tseka and Mokhotlong districts in Lesotho. The main objective is to find out effects of climate change on crop production. Data on climatic parameters especially rainfall and temperature and crop yields that are maize, beans and wheat of ten years from 2000 to 2010 were obtained. These were supplemented with primary data questionnaires. Information was obtained on ploughing method, use of improved seeds, types of soils, use of irrigation; information dissemination etc.A total of 100 farmers was interviewed. Regression analysis was used to find out effects of climate change on crop production. Frequency distribution analysis was also used for primary data. Research results show that climatic parameters have little impact on crop production. Other factors affecting crop production are types of soils, plouhging methods, use of improved seeds use of irrigation as most farmers are subsistence rain fed. Subsequent to these findings it is suggested that crop diversification, and crop intensification, irrigation development, conservation agriculture and development of climate change policy are suitable adaptation strategies that will help farmers to improve crop yields.
\end{abstract}

Key words: climate change, crop production and adaptation

\section{Introduction}

Climate change is a main and lasting change in the arithmetical distribution of weather patterns over long periods of time ranging from decades to millions of years. Climate change is caused by many factors both natural and human. The natural factors include; latitude, continental or marine location of an area, altitude, and topography. The latter includes burning of fossil fuel, deforestation; industrialization etc.This research was focused in Thaba-tseka and Mokhotlong districts, Lesotho highlands.Mokhotlongis found on $29^{\circ} 20^{\prime} \mathrm{S} 29^{\circ} 00^{\prime} \mathrm{E}$.It consist of the highest terrain in the maluti range and source of the Senqu river, it is Lesotho's primary watershed. It has population of approximately 97,713 with an area of $4,075 \mathrm{~km}^{2}$. Thaba - tseka is found on $29^{\circ} 30^{\prime} \mathrm{S} 28^{\circ} 40^{\prime} \mathrm{E}$ with an area of $4,270 \mathrm{~km}^{2}$ and population of approximately 129,881 .

Climate in Lesotho is temperate with the average rainfall over the entire country ranges from $300 \mathrm{~mm}$ to $1300 \mathrm{~mm}$. The highest rainfall are recorded in the northern part of the highlands while in lowlands mean annual rainfall ranges between $650 \mathrm{~mm}$ to $850 \mathrm{~mm}$ (Lesotho meteorological services 2001). According to Reizebos and Chakela (1985) the temperature regime may form a serious constraint for annual crops especially the occurrence of frost early in the spring or in fall that forms important climatic factors determining agricultural potentials. In adding up the authors point out that, temperature can be hazardous to some crops especially in combination with the occurrence of limited amounts of soil moisture. For most of the year, the Lesotho climate is characterized by clear skies with a mean of 8.8 hours of daily sunshine (NES, 2000) with great intensity because of the high altitude and the low levels of atmospheric pollution. Intergovernmental Panel on Climate Change ( IPCC) assessments indicate that most of the parts of the world are likely to experience negative impacts on food security e.g. disrupted farming could lead to falling crop yields in many regions, in case of health in tropical region, diseases might rise due to increased temperatures. No region is expected to escape the impacts of climate change, especially poor countries, such as Lesotho, whose majority populations are mainly dependent on natural resources for survival, are the most vulnerable to the negative impacts of climate change. In these countries, the impacts will directly and or indirectly affect human welfare and sometimes undercut the efforts to promote sustainable human development and environmental recovery. The country of Lesotho is heavily dependent on food imports to satisfy local consumption (Lesotho meteorological services 2001). There is need to research about how climate change has contributed to agricultural production in Lesotho.

\section{Materials And Methods}

The data from the department of meteorology services in Lesotho that is monthly rainfall, monthly minimum and maximum temperature of the past ten years was used from the year 2000 to 2010. The crop yields of maize, wheat and beans of the past ten years were used, from the year 2000 to 2010 this data was from 
Bureau of statistics and documentation from Ministry of Agriculture. A total of 100 farmers were interviewed using self administered questionnaires.

The regression analysis was used to show how independent variables of rainfall and temperatures affect crop yields. Pearson correlation was used to analyse effects of climatic parameters on crop production. Frequency distribution graphs were also used to analyse the distribution of rainfall, air temperature both minimum and maximum on crop production. . Error bars with mean and standard deviation were used to show distribution of monthly rainfall, minimum and maximum temperature in Mokhotlong and Thaba-tseka. Box plots were used to analyse crop production because they are most efficient graphics for examining data distribution and for making comparison between distributions. A frequency distribution analysis was used to analyse questionnaires and tables and graphs were produced.

\section{Results And Discussion}

The error bars are being used with Mean and Standard Deviation of monthly rainfall, minimum and maximum air temperature of Mokhotlong and Thaba-tseka districts. High standard deviation indicates that the data points are spread out over a large range of values. The low standard deviation indicates that the data points tend to be very close to the mean. Error bars are used to show distribution of monthly rainfall, minimum and maximum temperature in Mokhotlong and Thaba-tseka.

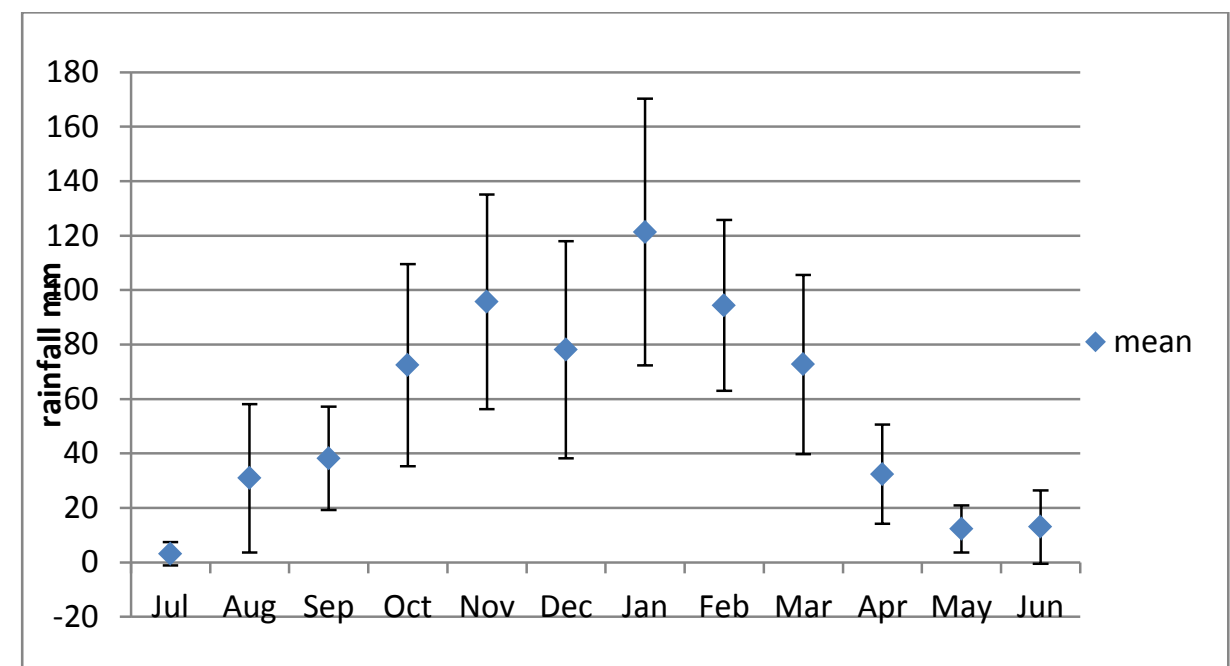

Figure 1 Thaba-tseka mean monthly rainfall from the year 2000 to 2010

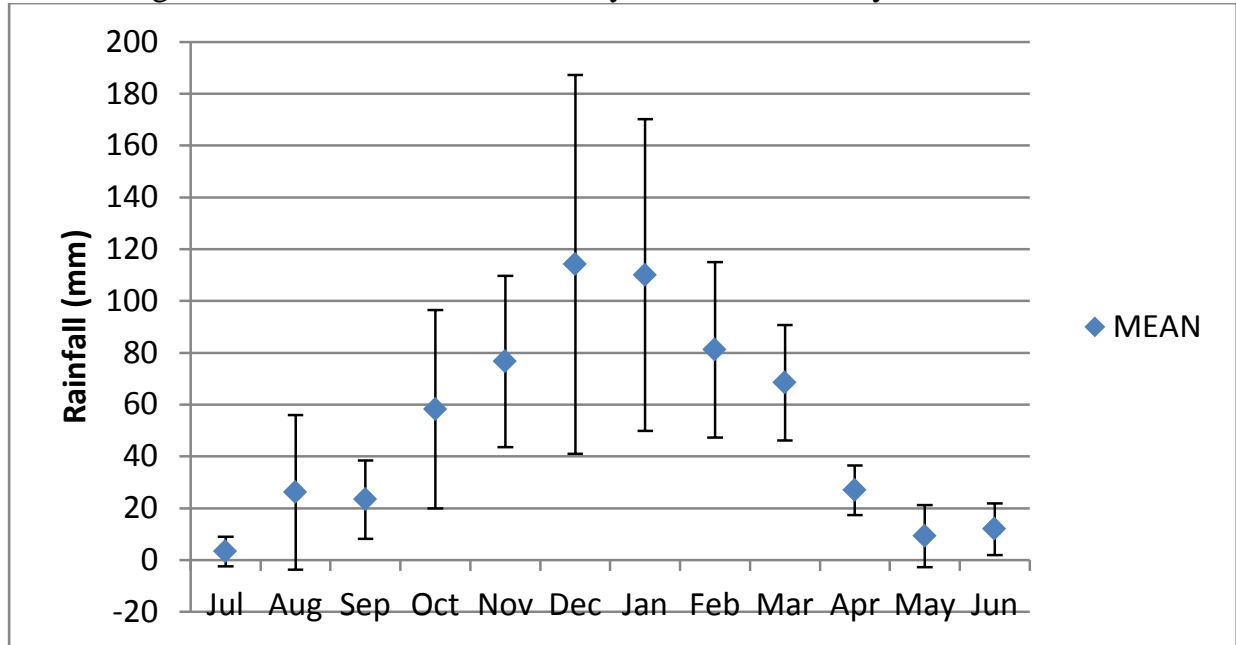

Figure 2 Mokhotlong mean monthly rainfall from the year 2000 to 2010

The mean monthly rainfall of Thaba-tseka for ten years showed that mean rainfall varied every month, and generally increased from July to January. But, the mean rainfall slightly decreased in December. Rainfall was decreasing from January to June. The same pattern occurred in Mokhotlong district as shown in Figure 2, where rainfall increased from July to January, and decreased from January to June From both figures it showed that high monthly rainfall (>50 mm) occurred during October to March, because Lesotho has a distinct rainfall season from October to April. Typically, $80 \%$ of the annual precipitation falls during this period, mainly from thunderstorms and instability showers (Sene et al.1998), with peak rainfall from December to February. 
In Thaba-Tseka district very little rain less than $20 \mathrm{~mm}$ occurred in May to July, as well as in Mokhotlong district. The error bars shown in Figure 1 and 2 indicated the standard deviation of rainfall of each month every year. Big standard deviation (SD), shown by long error bar indicates high variation of rainfall in a particular month every year. In contrary, the short error bars indicates low standard deviation, as well as low variation of rainfall in a particular month every year. The Highest variation of rainfall at Thaba-tseka district occurred in January, with SD $48.9 \mathrm{~mm}$ for Thaba-tseka. Rainfall distribution is strongly influenced by topographic variations (Seneetal.1998).According to Usman and Reason (2004) rainfall maybe particularly heavy over Lesotho if the cloud band only extends as far pole wards as eastern South Africa. According to (Richardson et al 2007; Tadesse et al 2008) illustrate that, rainfall over much of Southern Africa is highly variable both in space and time. This has major implications for human livelihoods, particularly for those areas where rural populations are reliant upon rain fed agriculture.

The standard deviation was very high and sensitive to crop production in both districts during these months August, October, November, December, January and February. The rainy season's start and its duration have been previously investigated for agricultural, to define the effective time to plant, to estimate the growing season's length, germination and seedling emergence (Benoit, 1977).

Maize is an efficient user of water in terms of total dry matter production and among cereals it is potentially the highest yielding grain crop (Doorenbos and Kassam, 1988). For maximum production a medium maturity grain crop requires between 500 to $800 \mathrm{~mm}$ of water depending on the climate of the area (Doorenbos and Kassam, 1988). According to Sprague and Dudley (1988), maize can be grown in areas where the annual precipitation ranges from $250 \mathrm{~mm}$ to over $500 \mathrm{~mm}$.

But Nield and Newman (1990) reported that, under dryland farming, maize is generally not grown in areas receiving less than $600 \mathrm{~mm}$ of annual precipitation. Stone et al. (1996) reports the maximum crop water use for maize as being around $600 \mathrm{~mm}$. Sommer et al (2013) show that the water requirement for wheat is about $600 \mathrm{~mm}$ per annum. In dry areas, where cultivation practices such as zero tillage and minimum tillage are practised, stubble mulching is recommended for moisture conservation. Frost can damage wheat, especially after the formation of ears in spring resulting in low yield. Beans cultivated under rainfed conditions the crop requires a minimum of 400 to $500 \mathrm{~mm}$ of rain during the growing season, but an annual total of 600 to $650 \mathrm{~mm}$ is considered ideal(Liebenberg A.J. 2002)

FAO report of (2008) showed thatthe climate change variables considered in the climate change and food security (CCFS) are gradual changes in precipitation: increase in the frequency, duration and intensity of dry spells and droughts changes in the timing, duration, intensity and geographic location of rain and snowfall, increase in the frequency and intensity of storms and floods greater seasonal weather variability and changes in start or end of growing seasons. This variability is not suitable for many crops.

UNEP report of (2006) showed that since 2001, consecutive dry spells in some areas of southern Africa have led to serious food shortages including Lesotho. If General Circulation Model (GCM) outputs are anything to go by, the ongoing droughts in southern Africa are not going to end any time soon. Indeed, the situation is expected to get worse with global warming. warmer and drier climate, characterised by increased frequency and intensity of El Niño events, will drastically reduce soil moisture and water runoff to rivers, thus hampering crop production which has a major influence on food security.

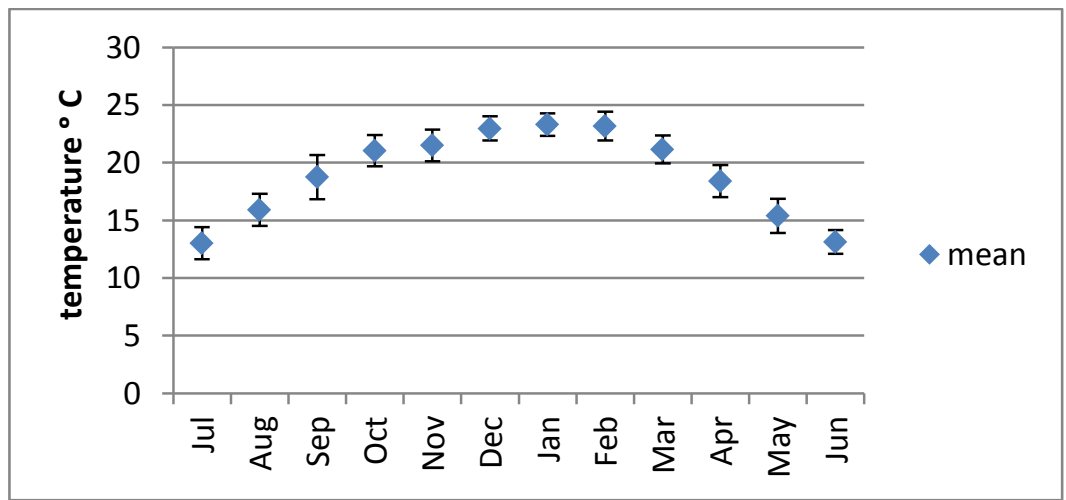

Figure 3 Thaba-tseka mean maximum temperatures from the year 2000 to 2010 


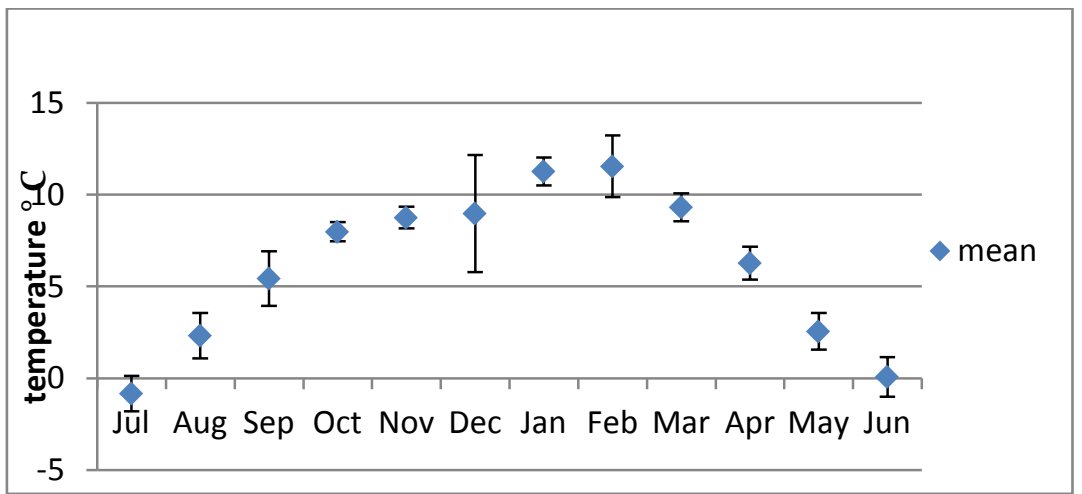

Figure 4 Thaba-tseka mean minimum temperatures from the year 2000 to 2010

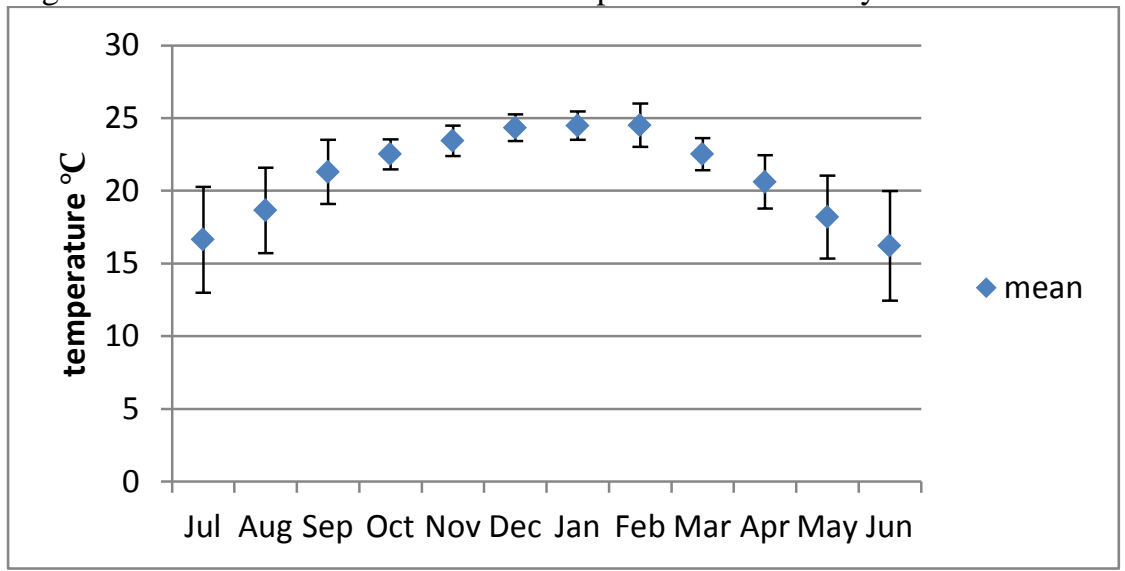

Figure 5 Mokhotlong mean maximum temperature from the year 2000 to 2010

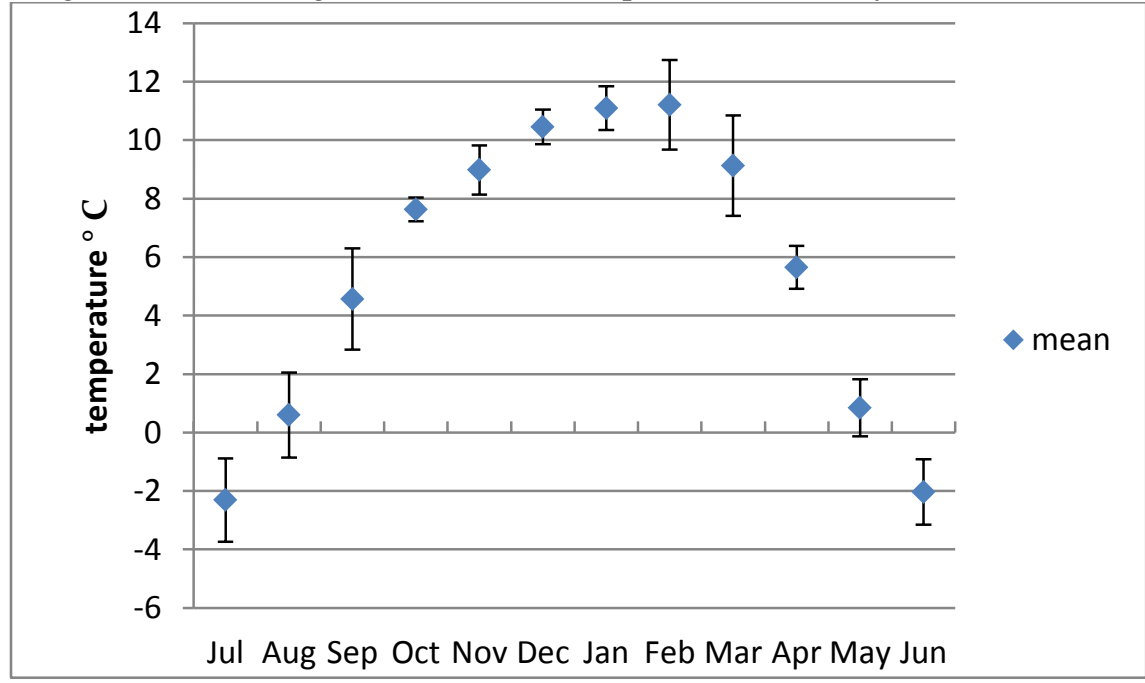

Figure 6 Mokhotlong mean minimum temperature from the year 2000 to 2010

The error bars of maximum temperature for the two districts shown on figure 3 and figure 5 above; maximum temperature were in the three months being December, January and February ranging from $22^{\circ} \mathrm{C}$ to $25^{\circ} \mathrm{C}$. The error bars showed high SD of $1.92^{\circ} \mathrm{C}$ in September and the lowest SD of 0.1 in January. The error bars of monthly minimum temperature for Thaba-tseka in figure 4 showed that in June and July temperatures were under $0^{\circ} \mathrm{C}$, the high SD of $3.2^{\circ} \mathrm{C}$ in December and the low SD of $0.5^{\circ} \mathrm{C}$ in October. The mean maximum monthly temperature variation of Thaba-tseka varied slightly in different months. Figure 5 showed that the high maximum monthly temperature with SD of $3.7^{\circ} \mathrm{C}$ in June and low SD of $0.1^{\circ} \mathrm{C}$ in December. The minimum monthly temperature of Mokhotlong shown in figure 6 showed that for June temperature is under $-3.7^{\circ} \mathrm{C}$ and July is $-3.5^{\circ} \mathrm{C}$. The high SD of $1.7^{\circ} \mathrm{C}$ in September and low SD of $0.4^{\circ} \mathrm{C}$ in October. Winters are dry, cold and dominated by high-pressure systems in Lesotho.

Temperature variability in Lesotho is influenced by both Indian and Atlantic oceans with wide differences. .According to Jones and Thornton, (2003)maize is a C4 crop and will be more tolerant of higher temperatures than a $\mathrm{C} 3$ crop such as beans; their results indicate that beans grown in almost all areas with 
elevations below $1000 \mathrm{~m}$, and in many of the areas up to $1500 \mathrm{~m}$, are likely to see yield reductions to 2050 . The temperature threshold above which yield reductions are indicated is about $20-22.8^{\circ} \mathrm{C}$. This compares well with the temperature of $20.8^{\circ} \mathrm{C}$ given by Boote et al. (1998) as being optimal for bean seed yield.

Beans production ranged from 156 to 734 metric tons (mt), whilst 1113 to $7187 \mathrm{mt}$ for wheat, and 5151 to $9736 \mathrm{mt}$ for maize. It showed in figure 7 that the production fluctuation of wheat and maize were higher than beans, shown by the whiskers interval of each commodity. High fluctuation means the inconsistency of production, which can suddenly decrease or increase. . This condition is very vulnerable for food security of any community in the world.

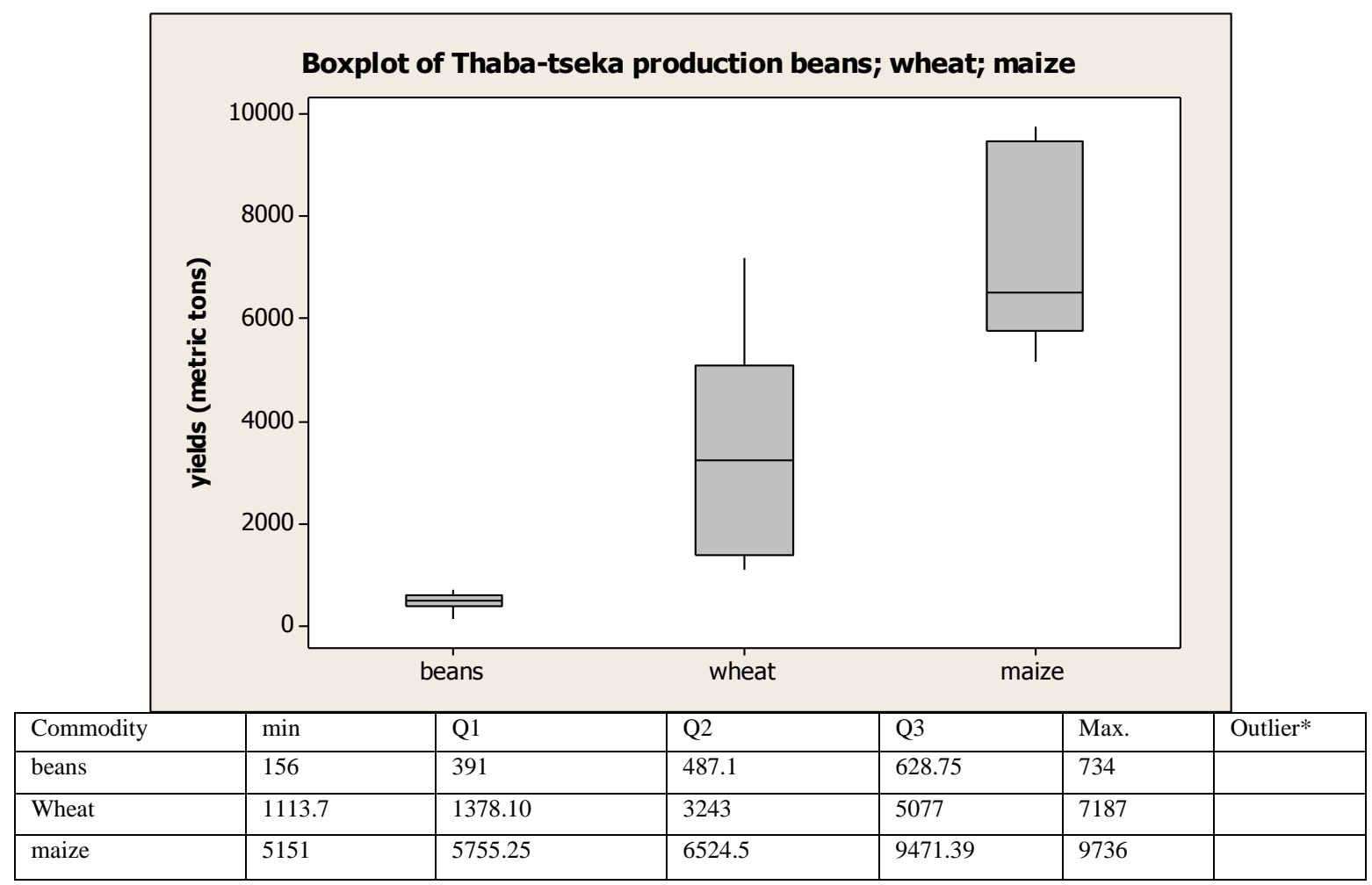

Figure 7 Thaba-tseka crop production of beans, wheat and maize. from the year 2000 to 2010

The high production variation of wheat and maize indicates that those commodities were very vulnerable to production factors, including climate. Every plant has its own specific optimal temperature for growth and a temperature range in which it flourishonce temperatures outside this range are encountered, the plant suffers and growth slows (GA, 2003). Thornton et al (2008) showed that,beans temperature driven yield increases will occur at higher elevations or up to average temperatures of about 20-22.8C. Beyond these temperatures, yields will tend to decline.Climate change variables influence biophysical factors such as plant growth, water cycles etc.The rate of growth and development of crops from planting to maturity is dependent mainly upon temperature. Maize is a crop with a rapid growth rate that yields best under moderate to warm temperatures. Cool temperatures slow down the progress to maturity and high temperatures hasten maturity (Brown, 1997).

Warm temperatures are suitable for summer wheat $\left(22^{\circ}\right.$ to $\left.34^{\circ} \mathrm{C}\right)$ and cool temperatures are suitable for winter wheat $\left(5^{\circ}\right.$ to $\left.25^{\circ} \mathrm{C}\right)$. According to Wheeler et al (2000) showed that in general, an increase in mean seasonal temperature of 2 to $4{ }^{\circ} \mathrm{C}$ reduces the yield of annual crops of determinate growth habit, such as wheat.Seed yields are particularly sensitive to brief episodes of hot temperatures if these coincide with critical stages of crop development. Hot temperatures at the time of flowering can reduce the potential number of seeds or grains that subsequently contribute to the crop yield.

An ideal climate for planting wheat can be described as cool and moist, followed by a warm dry season for harvesting. Rainfall occurs mainly during the summer season but is extremely variable in quantity and timing. Rainfall is higher in the mountains but the cropping season is much shorter due to the early onset of frost which will be intensified by climate change. The following that is hail, frost, snow and drought cause significant risks for agricultural production in Lesotho.Africa By 2020, in some countries, yields from rain-fed agriculture could be reduced by up to $50 \%$. Agricultural production, including access to food, in many African countries is projected to be severely compromised. This would further adversely affect food security (IPCC, 2007). 


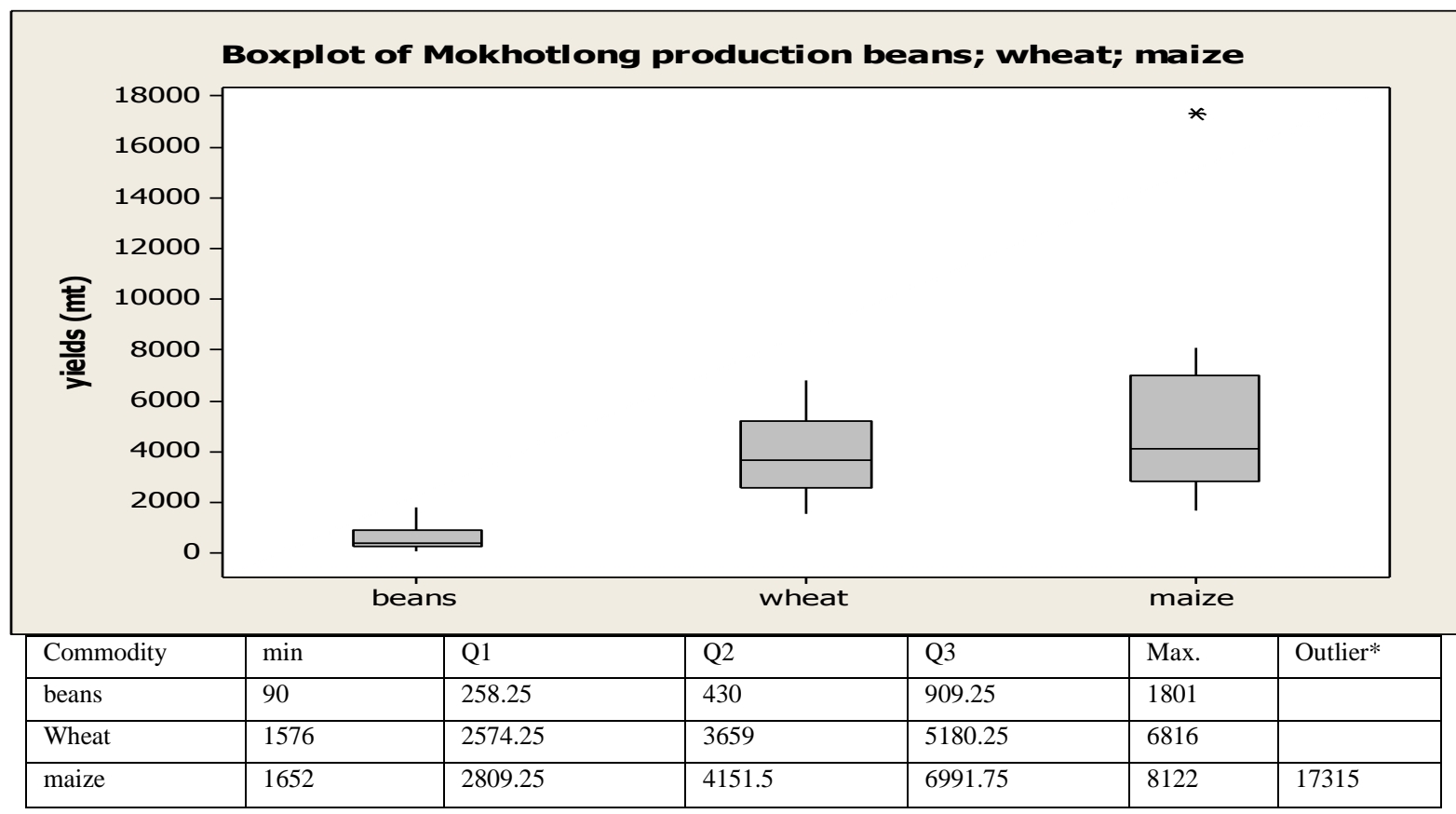

Figure 8 Mokhotlong cropproductionsof beans, wheat and maize from the year 2000 to 2010

The distribution of each commodity varied yearly especially for wheat and maize. Mokhotlong district had high fluctuation of maize production with the outlier of $17,315 \mathrm{mt}$ as compared to beans and wheat. The outlier means that there is particular period where the production was extremely higher. The extreme that is high or low crop production indicated the impact of climate change, where the production is not stable or gradually increase. Therefore, it could be concluded that maize production in Mokhotlong was vulnerable to climate change due to the extreme high maize yields.

Table 1 correlation between production and climatic parameters (rainfall, maximum and minimum temperature)

\begin{tabular}{|c|c|c|c|c|}
\hline \multirow{2}{*}{ Location } & Production & Rainfall $(\mathrm{mm})$ & $\begin{array}{c}\text { Maximum temperature } \\
\left({ }^{\circ} \mathrm{C}\right)\end{array}$ & $\begin{array}{c}\text { Minimum temperature } \\
\left({ }^{\circ} \mathrm{C}\right)\end{array}$ \\
\hline \multirow{3}{*}{ Thaba-tseka } & Beans & 0.118 & -0.489 & 0.419 \\
\cline { 2 - 5 } & Wheat & 0.300 & -0.334 & 0.051 \\
\cline { 2 - 5 } & Maize & 0.282 & 0.159 & 0.338 \\
\hline \multirow{2}{*}{ Mokhotlong } & Beans & -0.369 & 0.229 & -0.023 \\
\cline { 2 - 5 } & Wheat & -0.266 & 0.167 & -0.097 \\
\cline { 2 - 5 } & Maize & -0.128 & -0.203 & -0.199 \\
\hline
\end{tabular}

The Pearson correlation analysis results indicated that the correlation between crop production and climatic parameters in this study were very weak to moderate, since the $r$ scores ranged from 0.023 to 0.489 . The only moderate correlations are between beans production in Thaba tseka with both minimum and maximum temperatures, while others are weak to very weak correlations. These showed that climatic parameters (rainfall, maximum and minimum temperature) do not strongly effect crop production in Mokhotlong and Thaba-tseka means that there are other factors which are also affecting crop production.

\section{(a) Thaba-tseka}

a ploughing method $\square$ not using fertilizer

types of seeds variable rainfall

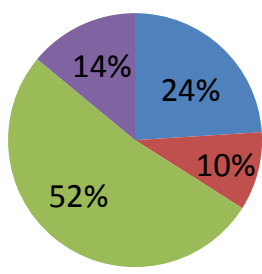

\section{(b) Mokhotlong}

ploughing method $\square$ not using fertilizer

types of seeds variable rainfall 
Figure 9 Farmers' responses on reasons of factors affecting crop production in Thaba-tseka (a) and Mokhotlong (b)

The decreasing or increasing of crop yield can be due to many reasons. In both districts farmers showed that the change in crop yields was affected by types of seeds followed by ploughing method and the variability of rainfall. Crop production can be increased by the use of quality seeds of high-yielding stresstolerant varieties, combined with judicious use of inputs, particularly water and nutrients (Rishi et al 2013).Many farmers are still using traditional animal drawn by oxen when ploughing their fields. According to Johansen et al (2012), the traditional animal drawn country plough has low output and high unit cost of operation whilst tractors are better machinery Rainfall variability had resulted in crop yields decrease in other parts of the world.

Some of the countries in the world are experiencing prolonged droughts because of climate change. The droughts led to decrease of crop production especially under rain fed. Biazin et al (2012) showed that, rainwater harvesting and management (RWHM) technologies hold a significant potential for improving rainwater-use efficiency and sustaining rainfed agriculture in the region of Sub-Sahara Africa. Rainwater harvesting adaptations to climate change in SSA should blend rainwater harvesting ideals with agronomic principles.

Information dissemination is very important, Laukkonen et al (2009) show that the vulnerability of individuals and communities to climate change impacts is not simply determined by the location of their settlements, but also by how those settlements are serviced, how effective and capable their local governments are and to what extent communities are able to cope with climate change impacts. It is widely accepted that the poorest communities are the most vulnerable, because they lack access even to the most basic urban services placing them at a comparative disadvantage and challenging their capabilities to take on additional stresses caused by climate change.

\section{Conclusion}

Climatic parameters (rainfall, maximum and minimum temperature) did not strongly affect crop production in Mokhotlong and Thaba-tseka. However other factors affecting crop production are those related to farmers' behaviour such as types of seeds used followed by ploughing method therefore there is a need for irrigated agriculture because it plays a vital role in providing general stability in the food production required to match with the population growth.

\section{Acknowledgements}

I express my gratitude to my supervisors for their support throughout this research.

\section{References}

[1]. Benoit P., 1977. The start of the growing season in northern Nigeria. Agricultural Meteorology 18(2),p 91-99.

[2]. Biazin Birhanu Geert Sterk, Melesse Temesgen, Abdu Abdulkedir, Leo Stroosnijder, 2012. Rainwater harvesting and management in rainfed agricultural systems in sub-Saharan Africa - A reviewPhysics and Chemistry of the Earth, Parts A/B/C, Volumes 47-48, 2012, p 139-151

[3]. Boote, K.J., Jones, J.W., Hoogenboom, G., 1998. Simulation of crop growth: CROPGRO model. In: Peart, R.M., Curry, R.B. (Eds.). Agricultural systems modeling and simulation. Marcel Dekker, Inc., New York, p. 651-692

[4]. Brown D.M. 1997Crop Heat Units for Corn and Other Warm Season Crops in Ontario. Availableat: http://www.uoguelph.ca/plant/research/ homepages/ttollena/research/assets, 9 March2011.

[5]. Doorenbos, J. and Kassam, H.A, 1988. Yield response to water. Irrigation and Drainage Paper number 33, 2nd edition. FAO, United Nations, Rome, p101 - 107, p 176

[6]. Food and Agriculture Organization FAO report 2008. The state of food insecurity in the world.

[7]. GA, 2003. Agroclimatic Atlas of Alberta: Agricultural Climate Elements. http://www1.agric.gov.ab.ca/\$department/deptdocs.nsf/all/sag6301?OpenDocument\# temp 10/05/2004

[8]. Intergovernmental Panel on Climate Change (IPCC) Fourth Assessment Report: Climate Change 2007 Geneva, Switzerland

[9]. Johansen C., M.E. Haque, R.W. Bell, C. Thierfelder, R.J. Esdaile, 2012 Conservation agriculture for small holder rainfed farming: Opportunities and constraints of new mechanized seeding systemsField Crops Research, Volume 132, 14 June 2012, p 18-32

[10]. Jones Peter G. and Thornton Philip K.2003 The potential impacts of climate change on maize production in Africa andLatin America in 2055 Global Environmental Change 13 (2003) p51-59

[11]. Laukkonen Julia, Paola Kim Blanco, Jennifer Lenhart, Marco Keiner, Branko Cavric, Cecilia Kinuthia-Njenga.2009. Combining climate change adaptation and mitigation measures at the local level.Habitat International, Volume 33, Issue 3, July 2009, p 287292.

[12]. Lesotho Meteorological services, 2001.Climate change in Lesotho. Ministry of Natural Resources. Maseru

[13]. Liebenberg A.J. 2002 .Dry bean production; department of agriculture.Pretoria.South Africa

[14]. Neild, R.E. and Newman, J.E., 1990. Growing Season Characteristics and Requirements in the Maize Belt-National Maize Handbook US. Available at http://www.agcom.purdue.edu/AgCom/Pubs/NCH/NCH-40.html 18/11/2003

[15]. NES (National Environment Secretariat) 2000.Biological diversity in Lesotho: a country study: Maseru: NES

[16]. Reibezos H and Chakela Q 1985.Natural resources and land suitability in Maseru district, Lesotho. Department of Geography, National University of Lesotho, Roma

[17]. Richardson FD,Hahn BD, Hoffman MT (2007) Modelling the sustainability and productivity of pastoral systems in the communal areas of Namaqualand. J Arid Environ 70:p701-717 
[18]. Rishi P. Singh, P. V. Vara Prasad, K. Raja Reddy,2013Chapter Two - Impacts of Changing Climate and Climate Variability on Seed Production and Seed IndustryAdvances in Agronomy, Volume 118, 2013, p 49-110

[19]. Sene K J, Jones DA, Meigh JR, Farquharson FAK 1998 Rainfall and flow variations in the Lesotho Highlands. International Journal of Climatology 18:p329-345

[20]. SommerR,GlazikinaM,Yuldashev T.,Otarov A.Ibraeve M.,Martynova L.,Bekenov M.,Kholov B.,Ibragimov N.,Kobilov R.,Karaev S.,Sultonov M,Khasanova F.,Esanbekov M.,Mavlyanov D.,Isaev S.,Abdurahimov S.,Ikramov R.,Shezdyukova L. And Pawn de E.2013 Impact of climate change on wheat productivity in central Asia.Agriculture, Ecosystem and Environment. Science direct

[21]. Sprague, G.F. and Dudley, J.W., 1988. Corn and Corn Improvement.3rd Edition. American Society of Agronomy, Inc. Madison, U.S. p $578-638$

[22]. Stone, L.R., Schelgel, A.J., Gwin, R.E. and Khan, A.H., 1996. Response of corn, grain sorghum, and sunflower to ir rigation in the High Plains of Kansas. Agricultural Water Management 30, 251-259

[23]. Tadesse T, Haile M, Senay G, Wardlow BD, and Knutson CL 2008 The need for integration of drought monitoring tools for proactive food security management in sub-Saharan Africa. Nat Resource Forum 32:265-279

[24]. Thornton P., Herrero M., Freeman A., Mwai O., Rege E., Jones P., and McDermott J., 2008." Vulnerability, Climate change and Livestock - Research Opportunities and Challenges for Poverty Alleviation" ILRI, Kenya

[25]. Wheeler T. R., Craufurd P. Q., Ellis R. H., Porter J. R., Prasad P. V. V. 2000 Temperature variability and the yield of annual crops. Agric. Ecosyst. Environ. 82,p 159-167

[26]. UNEP 2006. Climate Change Climate and Variability in Southern Africa: Impacts and Adaptation in the Agricultural Sector.

[27]. Usman MT, Reason CJC (2004) Dry spell frequencies and their variability over southern Africa Climate Research 26:p199-211 